\title{
Planning the improvement of a seismic network for monitoring active volcanic areas: the experience on Mt. Etna
}

\author{
A. D’Alessandro ${ }^{1}$, L. Scarfî ${ }^{2}$, A. Scaltrito ${ }^{2}$, S. Di Prima ${ }^{2}$, and S. Rapisarda ${ }^{2}$ \\ ${ }^{1}$ Istituto Nazionale di Geofisica e Vulcanologia, Centro Nazionale Terremoti, Roma, Italy \\ ${ }^{2}$ Istituto Nazionale di Geofisica e Vulcanologia, Osservatorio Etneo - Sezione di Catania, Catania, Italy \\ Correspondence to: A. D’Alessandro (antonino.dalessandro@ingv.it)
}

Received: 31 May 2013 - Revised: 17 September 2013 - Accepted: 25 September 2013 - Published: 23 October 2013

\begin{abstract}
Seismology and geodesy are generally seen as the most reliable diagnostic tools for monitoring highly active or erupting volcanoes, like Mt. Etna. From the early 1980's, seismic activity was monitored at Mt. Etna by a permanent seismic network, progressively improved in the following years. This network has been considerably enhanced since 2005 by 24-bit digital stations equipped with broad-band ( $40 \mathrm{~s}$ ) sensors. Today, thanks to a configuration of 33 broadband and 12 short-period stations, we have a good coverage of the volcanic area as well as a high quality of the collected data. In the framework of the VULCAMED project a workgroup of Istituto Nazionale di Geofisica e Vulcanologia has taken on the task of developing the seismic monitoring system, through the installation of other seismic stations. The choice of optimal sites must be clearly made through a careful analysis of the geometry of the existing seismic network. In this paper, we applied the Seismic Network Evaluation through Simulation in order to evaluate the performance of the Etna Seismic Network before and after the addition of the stations in the candidate sites. The main advantage of the adopted method is that we can evaluate the improvement of the network before the actual installation of the stations. Our analysis has permitted to identify some critical issues of the current permanent seismic network related to the lack of stations in the southern sector of the volcano, which is nevertheless affected by a number of seismogenic structures. We have showed that the addition of stations at the candidate sites would greatly extend the coverage of the network to the south by significantly reducing the errors in the hypocenter parameters estimation.
\end{abstract}

\section{Introduction}

Mt. Etna in Sicily (southern Italy) is one of the most active volcanoes in the world and, for this reason, it is considered by the scientific international community as one of the most intriguing natural laboratories for the understanding of eruptive processes and lava uprising.

Systematic observations of seismic activity at Mt. Etna began in 1967, when one mechanical seismometer was permanently deployed in the southern flank of the volcano, ca. $7 \mathrm{~km}$ apart from the summit craters (Bottari and Riuscetti, 1967). Previous investigations were limited to macroseismic observations and analyses of seismograms registered by a mechanical instrument and then collected by the astronomical observatory operating at the University of Catania.

A new impulse for seismic observations came in 1978 when a short-period telemetered network was set up permanently by the University of Catania. But it is only from the early 1990's, thanks to the Istituto Internazionale di Vulcanologia and the Poseidon Project, which merged into the Istituto Nazionale di Geofisica e Vulcanologia (INGV) in 2001, that seismic data have been available in digital format for a sufficient number of stations, increased in time as well as for three-component sensors. These improvements have allowed to put high-quality constraints on seismic activity occurring in recent years and to perform studies which tackle the link between seismicity and eruptive activity. Important results obtained during recent decades, mainly due to the rapid improvement in the seismic and deformation monitoring networks, have identified the main tectonic structures and the paths along which the magma rises beneath Mount Etna (e.g. Alparone et al., 2012 and reference therein). 


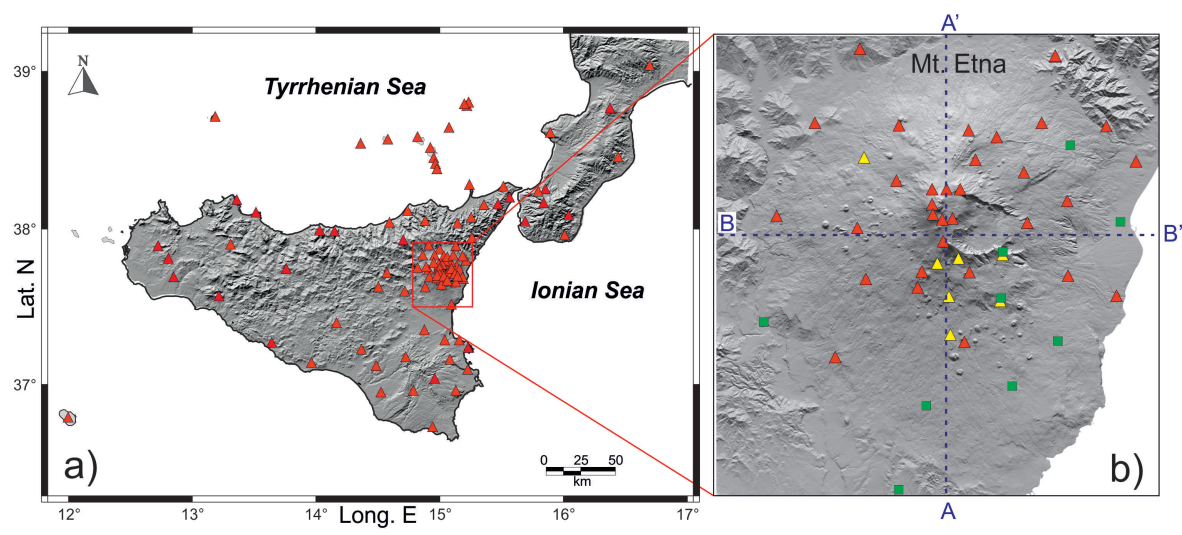

Fig. 1. (a) Seismic stations currently deployed in Sicily and the Southern Calabria (Italy) and detail of Etna volcano; red triangles are digital stations; yellow triangles are analogical stations; green squares are candidate sites; blue dashed lines indicate the cross sections $\mathrm{AA}^{\prime}$ and $\mathrm{BB}^{\prime}$ reported in Figs. 8 and 9 (see text for more details).

Since 2002, the main objectives of the seismological technical team at INGV - Osservatorio Etneo were those of a complete technological renovation, homogenization and densification of the Permanent Seismic Network used to monitor active tectonic and volcanic areas of Sicily. The seismic network (Fig. 1) covers eastern Sicily more densely, from the Aeolian archipelago to the Hyblean region, including the area of the Strait of Messina and the areas of active volcanism, such as Etna, Stromboli and Vulcano, and it consists of about one hundred seismic stations. The technological upgrade, together with the introduction of infrasonic sensors, accelerometers, and in the near future of sensors based on Micro Electro-Mechanical Systems technology (D'Alessandro and D'Anna, 2013), has the aim to realize a new advanced integrated Etna Seismic Network (ESN). ESN actually includes some analogical stations (Fig. 1) with short period sensors that will be kept in operation until they are gradually replaced with digital ones.

The upgrade of the seismic monitoring system operating in eastern Sicily has allowed both to improve the detection capabilities and the application of the latest analytical techniques for the study of seismic sources. This objective was achieved through the gradual replacement of existing analogical equipment with digital stations, equipped with broadband sensors, and digital transmission via satellite, UHF radio and WLAN. The improvement and/or the complete rebuilding of the infrastructures and supply systems, like solar photovoltaics, and in some cases the use of hybrids with methanol fuel cells, were of fundamental importance for the continuity of the acquisition chain.

Present day, in the framework of the VULCAMED project developed under the National Operational Programme "Research and Competitiveness" 2007-2013, an INGV workgroup has taken on the task of developing the seismic monitoring system, through the installation of new measurement stations; the aim is to further enhance the operational capabilities in research and volcanic monitoring in Southern Italy.

By considering the spatial distribution of earthquakes in the area, the presence of seismogenic structures and through an extensive site verification by geological-geophysical surveys, some potential new sites were identified. In the following months, some of these sites will complement the existing network. The choice of optimal sites must clearly be made through a careful analysis of environmental noise, of the possible logistics, technical and broadcast problems, but it must also take into account the geometry of the existing seismic network.

In this paper we applied the Seismic Network Evaluation through Simulation (SNES) method (D'Alessandro et al., 2011a) to ESN, in order to evaluate the location performance, along with the magnitude detection threshold of the network, before and after the addition of the stations in the candidate sites. In the last years the SNES method was widely used to analyse the network performance of many seismic networks (D'Alessandro et al., 2011a, 2012a, 2013a, c; D'Alessandro and Ruppert, 2012; D'Alessandro and Stickney, 2012). The SNES method allows determining, as a function of magnitude, hypocentral depth and confidence level, the spatial distribution of the following parameters: magnitude detection threshold, number of active stations in the location procedure, azimuthal gap and confidence levels of hypocentral parameters. Details on the SNES method and on the computation algorithms can be found in D'Alessandro et al. (2011a, b, 2012a, 2013a, c), D'Alessandro and Ruppert (2012), and D'Alessandro and Stickney (2012).

\section{Vulcanic and seismic activity on Mt. Etna}

Mt. Etna volcano is located along the boundary of the African and European plates, in a region of great geological and structural complexity, where the structural units of the 


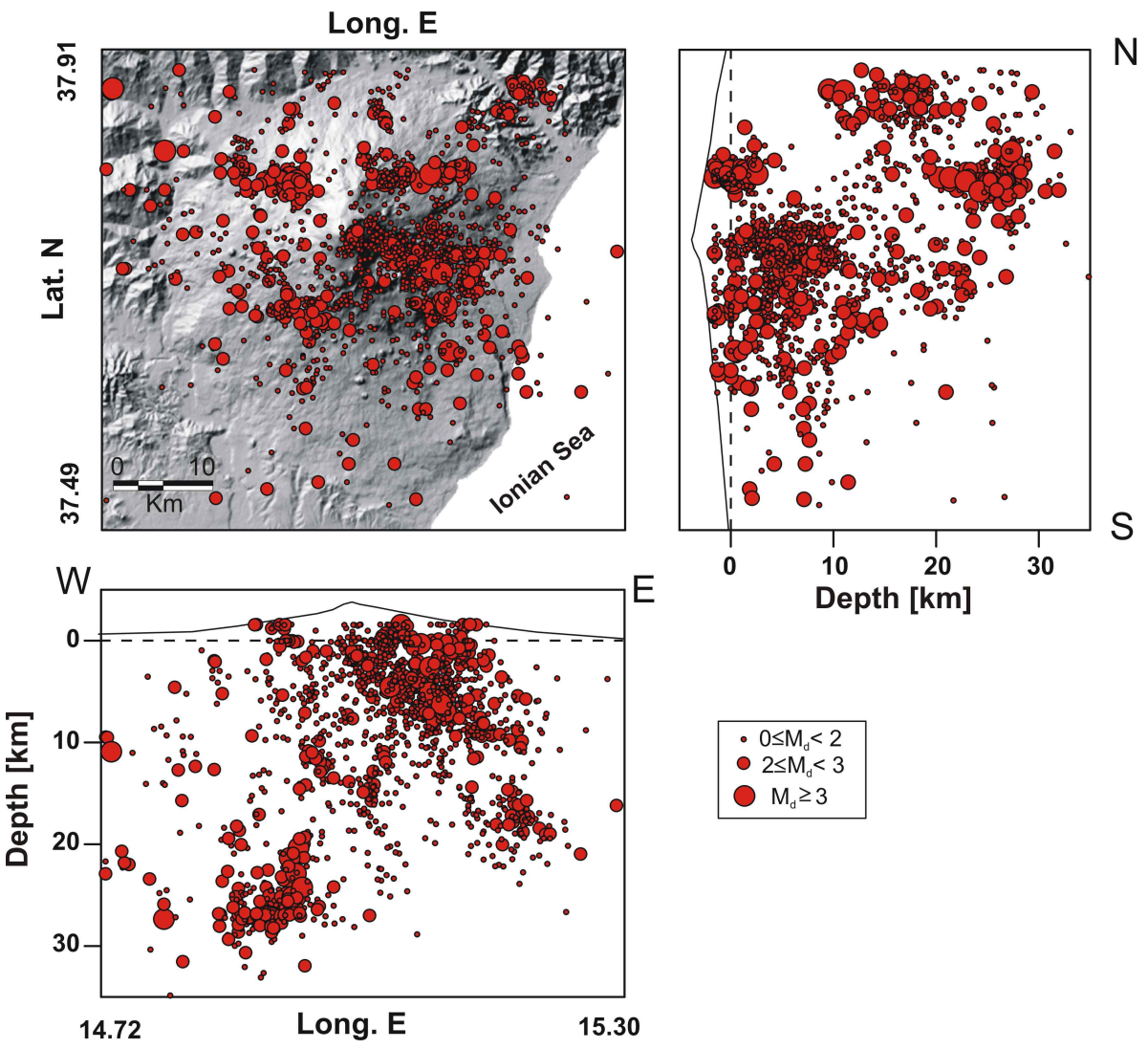

Fig. 2. Maps of the seismicity located by ESN for the period 2010-2012.

Appennine-Maghrebian Chain, the Hyblean Foreland, and the Ionian oceanic basin are identified (Fig. 2).

Volcanic activity of Etna is principally focused at both summit craters and lateral flanks. During the past $400 \mathrm{yr}$, the volcano has produced over sixty flank eruptions (Branca and Del Carlo, 2004), while the summit craters are almost continuously active, with persistent degassing and frequent explosive activity and lava fountaining at the vents on the crater floor. The flank eruptions are characterized by dike propagation associated with opening of eruptive fractures, generally oriented along two main rift zones: the northeast (NE) rift and the south (S) rift. The recent 2001 and 2002-2003 eruptions were heralded by intense seismicity, ground deformation and fracturing (e.g., Barberi et al., 2004; Bonaccorso et al., 2004; Gambino et al., 2004; Arevalo et al., 2005).

The main issue at Mt. Etna is the complex link between volcanism, seismicity and deformation pattern. Imminent eruptive activity has been detected through volcanic tremor analysis (e.g., Di Grazia et al., 2006; Falsaperla et al., 2011) and recharge phases have been well imaged by ground deformation, which showed an almost continuous expansion of the volcano (e.g., Patanè et al., 2005; Bonforte et al., 2008, and references therein). However, an important contrast in the deformation pattern characterizes the eastern flank which shows a fairly continuous seaward motion (e.g., Bonforte et al., 2011) and which is influenced by several fault segments (e.g., the Pernicana fault, the Timpe fault system, the Trecastagni and Tremestieri faults; see Azzaro et al., 2012, 2013). Moreover, the complex interactions between regional and local processes (Patanè et al., 2004; Scarfì et al., 2013) causes a frequent seismic activity. In particular, the eastern flank of Mount Etna is affected by local seismicity which might cause considerable damage despite its moderate magnitude (Azzaro, 2004). In Fig. 3, we show the seismicity occurred in the last three years, which can be considered as well representative of the most active seismogenetic structures in the last decade.

\section{Evaluation of the ESN performance}

In order to detect and locate small magnitude earthquakes, a seismic network requires dense and well distributed lownoise stations. It is important to assess existing network capabilities, in order to identify seismogenic areas that are not adequately covered and to quantify measures that will allow network improvement. Before installing the seismic stations in the candidate sites (CS), it should be therefore opportune to quantify the improvement in terms of coverage, decrease in magnitude detection threshold and improvement 

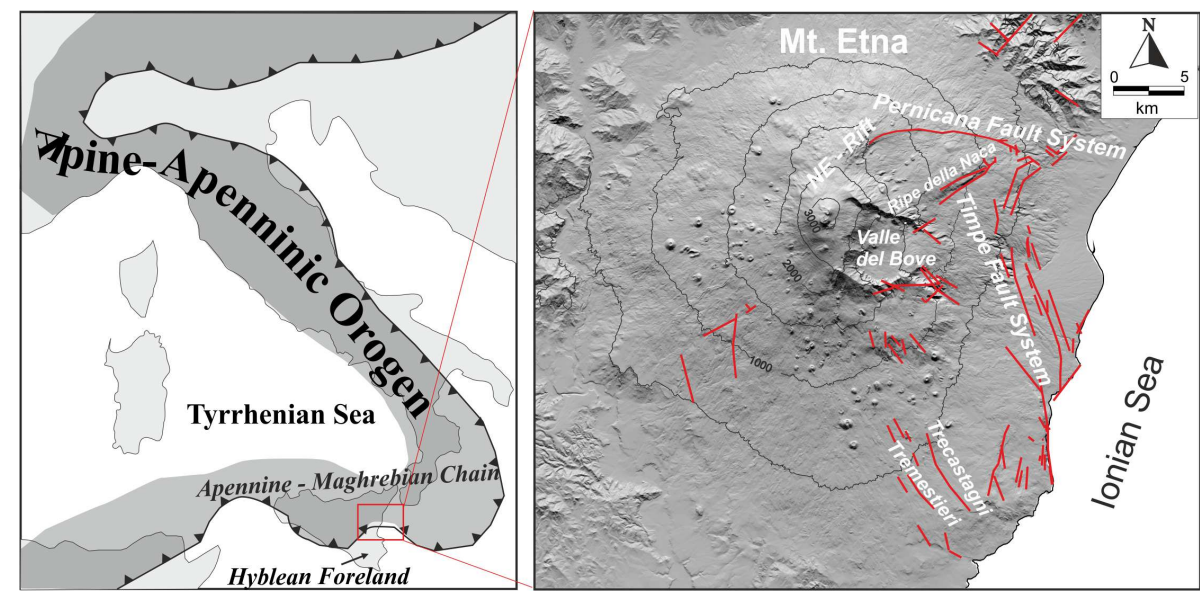

Fig. 3. Maps illustrating the main tectonic and structural features of the studied area (modified from Scarfì et al., 2013).

(a) Magnitude detection threshold

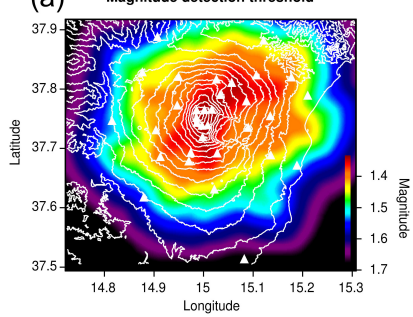

(b)

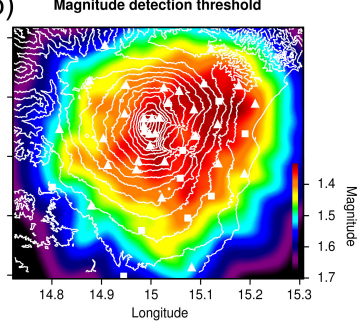

(c) Magnitude detection threshold

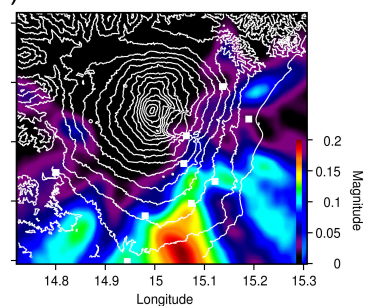

Fig. 4. Magnitude detection threshold maps determined for (a) ESN, (b) ESN+CS and (c) (ESN+CS)-ESN.

in hypocenter location. This would allow to identify in advance changes in the network geometry that would ensure a better coverage in the area to be monitored.

To evaluate the contribution of the CS in the framework of local seismicity, we applied the SNES method at two networks configuration: ESN, ESN+CS. In our simulation, we have considered only the modern digital stations of the ESN because the analogical stations will soon be replaced by modern stations and then the sites reconsidered. We discretized the study area using a square mesh having $250 \mathrm{~m}$ sides. A lot of earthquakes located in the Etna area have shallow hypocenters $(<5 \mathrm{~km})$ and so, in our simulation, we set the hypocentral depth to $5 \mathrm{~km}$. To mitigate the random noise a 2 $\mathrm{D}$ moving average with square windows having 5-point sides was applied to the maps, followed by a cubic 2-D spline interpolation to improve the graphics.

Figure 4 shows the magnitude detection threshold $\left(M_{\text {Det }}\right)$ maps determined for ESN, ESN+CS and (ESN+CS)-ESN, with $95 \%$ confidence level. The $M_{\text {Det }}$ maps are determined by considering only those earthquakes able to activate at least four stations. The $M_{\text {Det }}$ map shows that the ESN (Fig. 4a) is able to detect all the seismic events with $M_{\mathrm{L}} \geq 1.6$ with epicentre in the volcanic edifice. The $M_{\text {Det }}$ drops below 1.4 only in the northern-centre of the volcano. The seismogenic structures further south, as the Trecastagni and Tremestieri faults are not well covered. The addition of CS (Fig. 4b) would ex- tend to these faults the area with $M_{\text {Det }} 1.4$. The map of Fig. $4 \mathrm{c}$ shows that the area with the greatest improvement is clearly is the southernmost part of Etna volcano, where the decrease in $M_{\text {Det }}$ is about 0.2 .

However, the $M_{\text {Det }}$ does not take into account the uncertainty in the hypocenter parameters estimations. These are function of the velocity model and geometry, density and noise of the stations which make up the seismic network, so the $M_{\text {Det }}$ can significantly overestimate the level of coverage of a network (D'Alessandro et al., 2011a, b, 2012a, 2013a, c; D'Alessandro and Ruppert, 2012; D'Alessandro and Stickney, 2012).

Figures 5, 6 and 7 show the SNES maps estimated for $M_{\mathrm{L}}$ 1.5 , with $95 \%$ confidence intervals, for the ESN, ESN+CS and (ESN+CS)-ESN, respectively. Each SNES map is divided into six sub-maps which report the number of active stations in the location procedure, the azimuthal gaps and the amplitude of the confidence interval of origin time, latitude, longitude and hypocentral depth (D'Alessandro et al., 2011a). Uncertainties in the hypocenter coordinates were represented up to $5 \mathrm{~km}$.

The errors shown in the SNES maps may appear quite high compared to those reported in the seismic bulletin or in other published papers, but we must consider that they take into account both the geometry of the stations, and the error introduced by the use of a 1-D velocity model for a very complex 

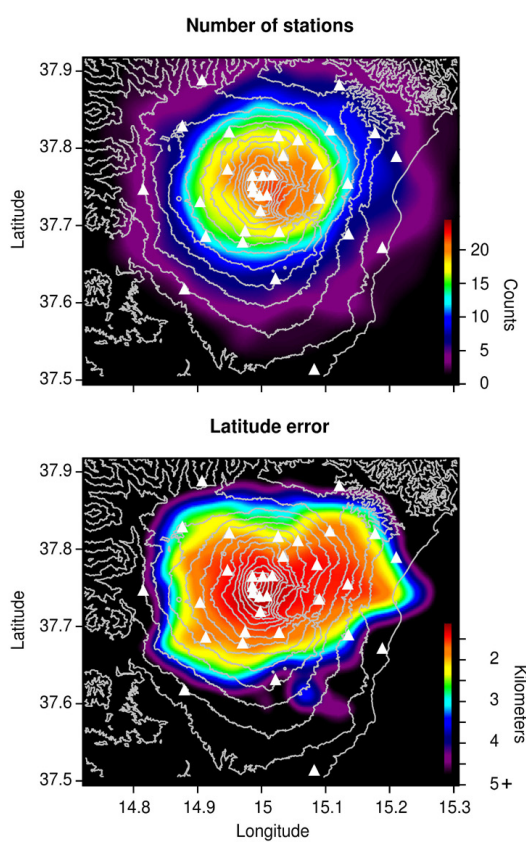

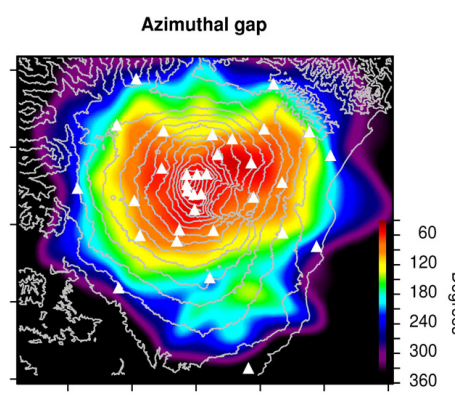

Longitude error

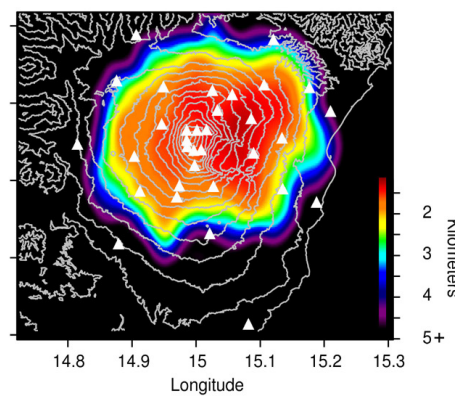

Origin time error

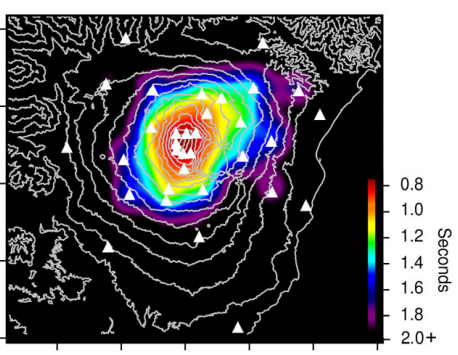

Depth error

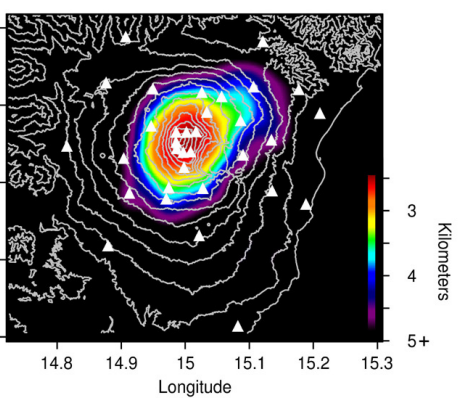

Fig. 5. SNES maps for ESN at $M_{\mathrm{L}} 1.5$, hypocentral depth of $5 \mathrm{~km}$ and confidence level of $95 \%$.
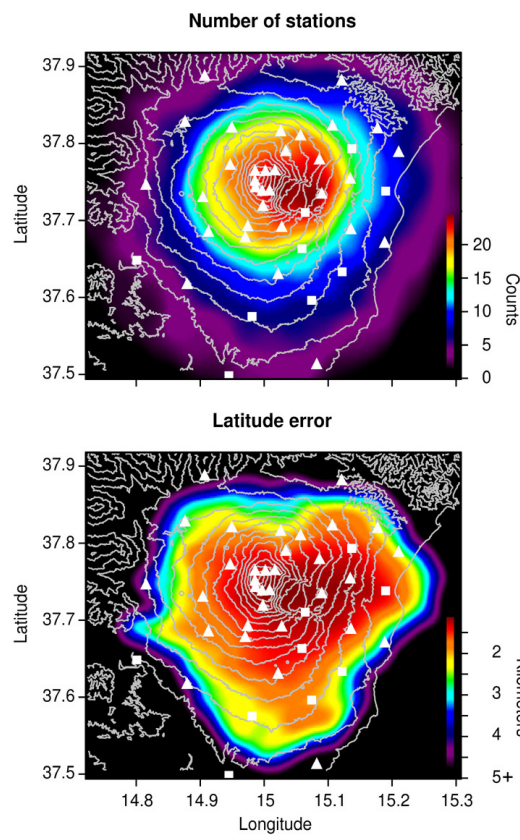

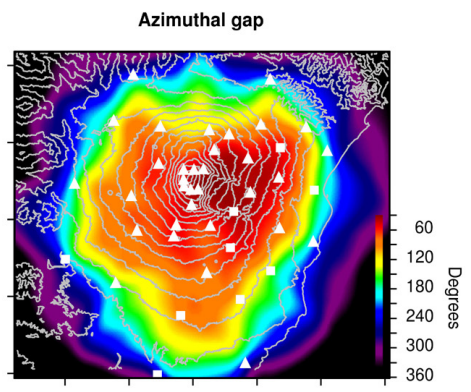

Longitude error

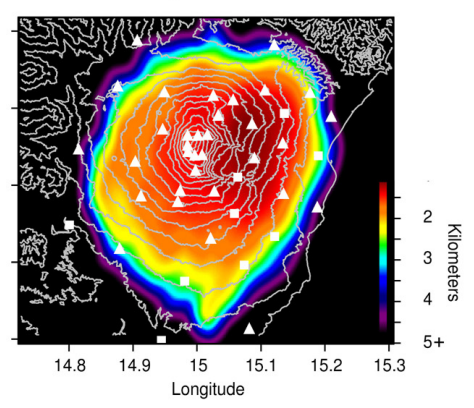

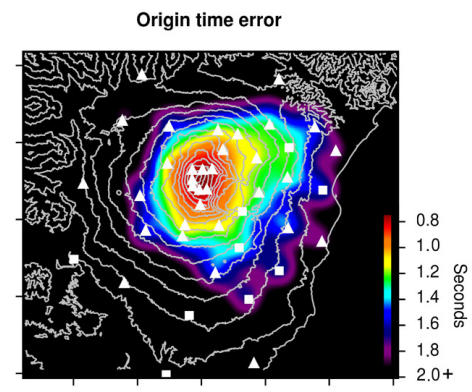

Depth error

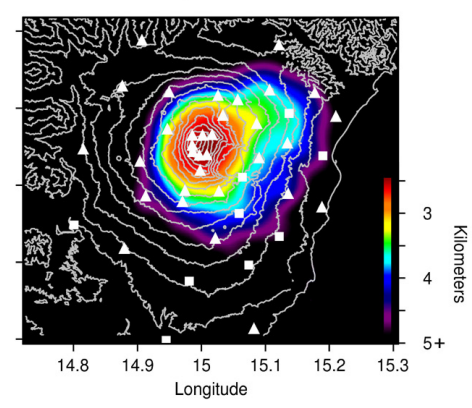

Fig. 6. SNES maps for ESN+CS at $M_{\mathrm{L}} 1.5$, hypocentral depth of $5 \mathrm{~km}$ and confidence level of $95 \%$.

geological area, and, finally, that they have been determined for a confidence level of $95 \%$.

Figure 5 shows that for $M_{\mathrm{L}} 1.5$ the maximum number of active stations in the localization process is about 20, in correspondence of the Valle del Bove. The azimuthal gap reaches a value of $60^{\circ}$ in a wide area in the central and northern parts of the volcanic edifice. The error in latitude and longitude assumes a quite complex shape. While the central and most northern part of the volcanic edifice is well covered, with average errors in the estimation of the epicentre of about $2 \mathrm{~km}$, the southernmost part is not well covered. The hypocentral depth, that, as well known, is the most difficult parameter to estimate, can be determined with acceptable 

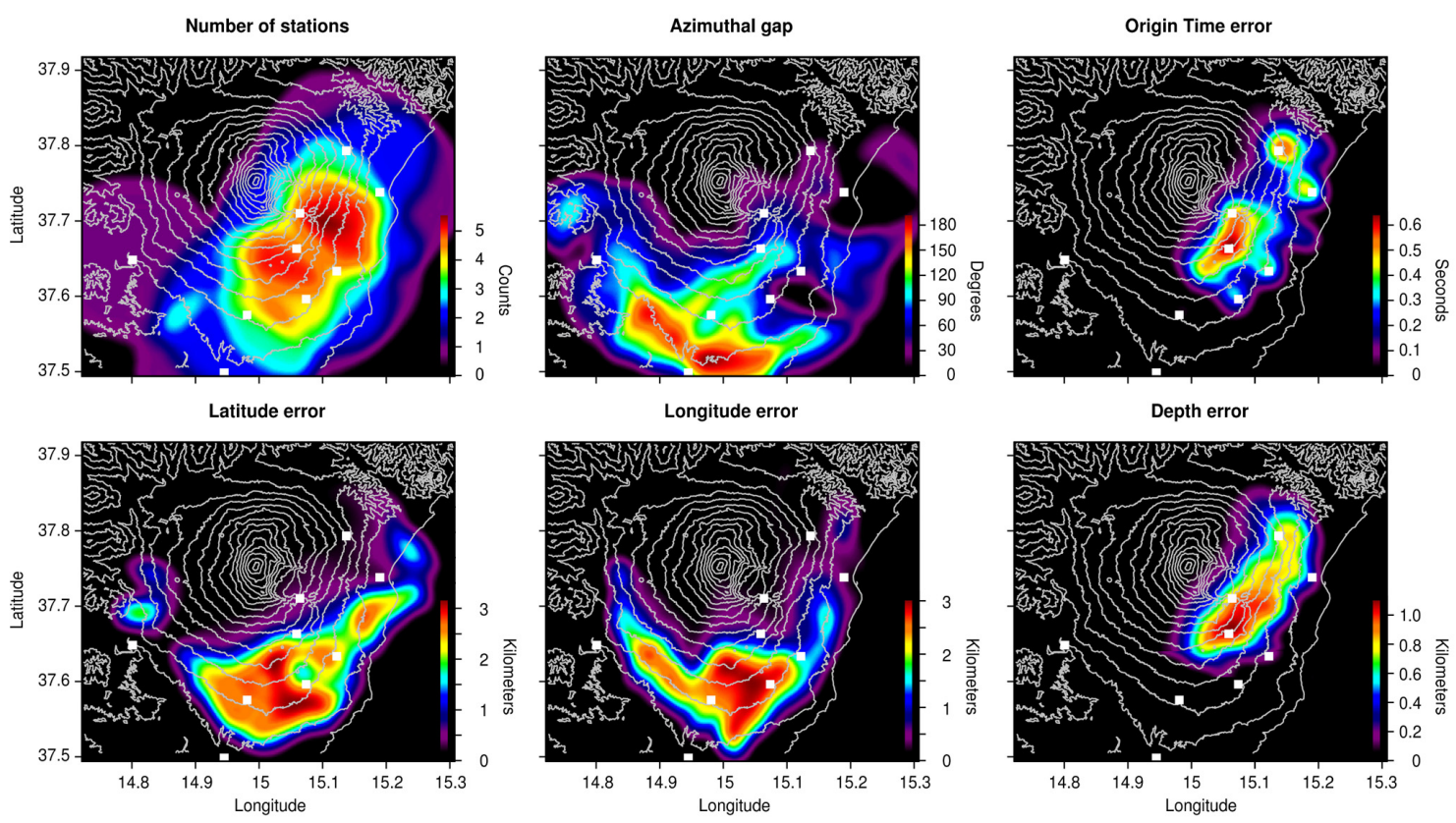

Fig. 7. SNES maps for (ESN+CS) $-\mathrm{ESN}$ at $M_{\mathrm{L}} 1.5$, hypocentral depth of $5 \mathrm{~km}$ and confidence level of $95 \%$.
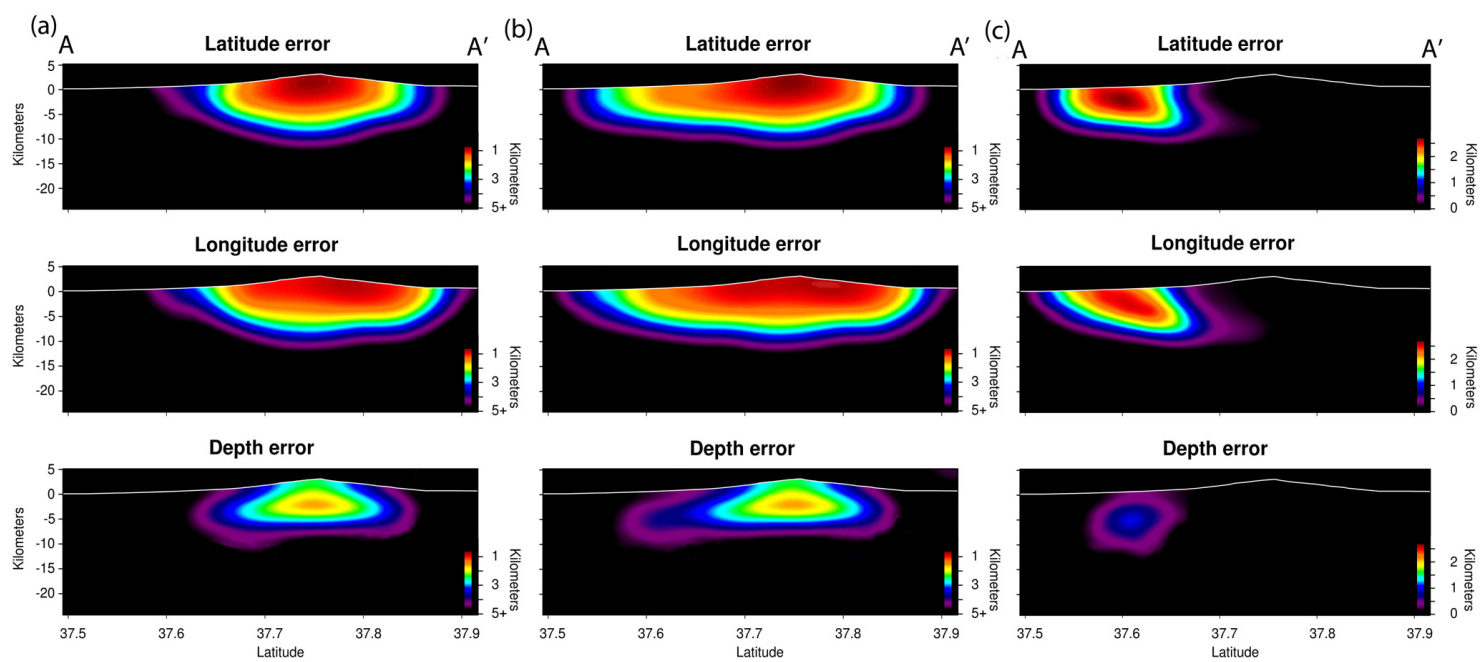

Fig. 8. Vertical section of hypocenter location uncertainty estimates between points $\mathrm{A}\left(37.495^{\circ} \mathrm{N}, 15.00^{\circ} \mathrm{E}\right)$ and $\mathrm{A}^{\prime}\left(37.92^{\circ} \mathrm{N}, 15.00^{\circ} \mathrm{E}\right)$, for $M_{\mathrm{L}} 1.5$ and confidence level of $95 \%$ (see Fig. 3), respectively for (a) ESN, (b) ESN+CS and (c) (ESN+CS)-ESN.

errors only at the summit of the Etna volcano and in a small area corresponding to the Pernicana Fault System.

Figure 6 shows that the maximum number of active stations in correspondence of the Valle del Bove would rise to 25 while the azimuthal gap would drop to about $60^{\circ}$ or less even in a large area south of the latter. The epicentres would be better constrained in almost all the southern part of the Etna edifice. In addition, hypocentral depth would be better constrained, but only in a small area of the eastern sector of the volcano.
Figure 7 allows to easily quantifying the improvement of coverage because of the addition of CS. In a large area of the southern sector, the number of stations able to detect an earthquake with $M_{\mathrm{L}} 1.5$ would rise by at least three units. In the southernmost part of the volcanic edifice, the azimuthal gap could be reduced by more than $180^{\circ}$. The error in latitude and longitude could be reduced by more than $3 \mathrm{~km}$ in the southernmost area, while the error in the hypocentral depth could be decreased in the central eastern part of the volcano.

Figure 8 and 9 show the vertical sections of hypocenter location uncertainty estimates between points A $\left(37.495^{\circ} \mathrm{N}\right.$, 


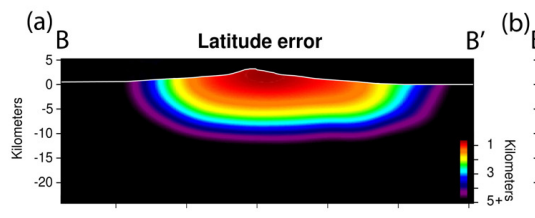

Longitude error
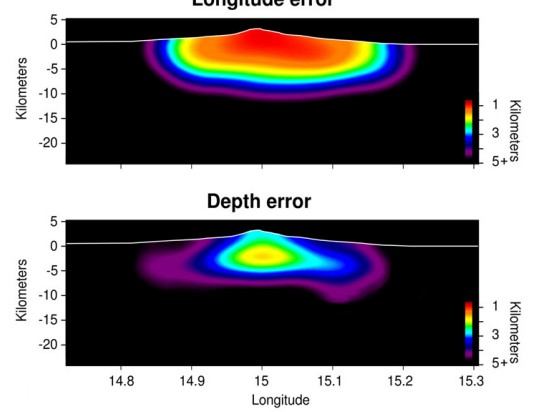

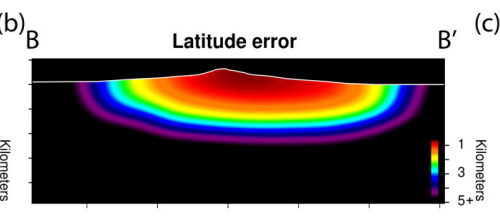

Longitude error
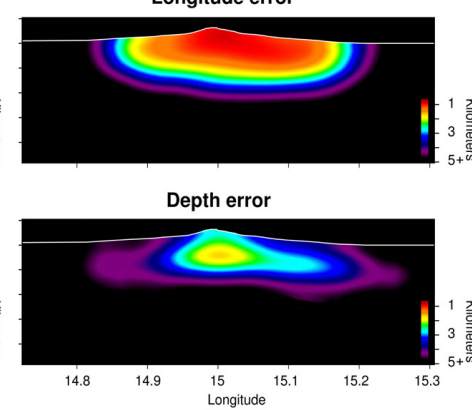

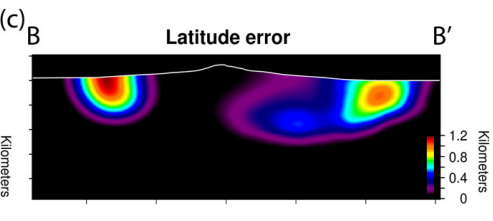

Longitude error
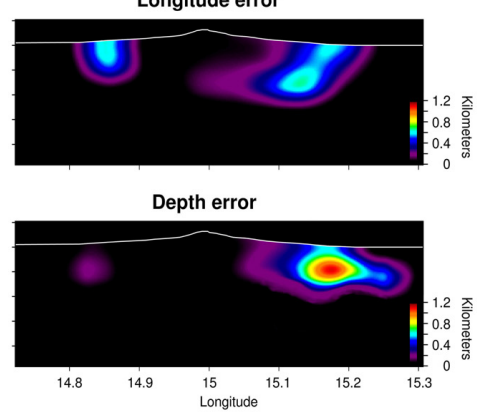

Fig. 9. Vertical section of hypocenter location uncertainty estimates between points $\mathrm{B}\left(37.75^{\circ} \mathrm{N}, 14.72^{\circ} \mathrm{E}\right)$ and $\mathrm{B}^{\prime}\left(37.75^{\circ} \mathrm{N}, 15.31^{\circ} \mathrm{E}\right)$, for $M_{\mathrm{L}} 1.5$ and confidence level of $95 \%$ (see Fig. 3), respectively for (a) ESN, (b) ESN+CS and (c) (ESN+CS)-ESN.

$\left.15.00^{\circ} \mathrm{E}\right)$ and $\mathrm{A}^{\prime}\left(37.92^{\circ} \mathrm{N}, 15.00^{\circ} \mathrm{E}\right)$, and $\mathrm{B}\left(37.75^{\circ} \mathrm{N}\right.$, $\left.14.72^{\circ} \mathrm{E}\right)$ and $\mathrm{B}^{\prime}\left(37.75^{\circ} \mathrm{N}, 15.31^{\circ} \mathrm{E}\right)$, respectively, also showed in Fig. 3. The sections of Fig. 8 cross the Etna volcano from South to North while that of Fig. 9 from East to West. Figures 8a and 9a indicate that the ESN is able of locating events with $M_{\mathrm{L}} 1.5$, with acceptable errors, until a depth of about $10 \mathrm{~km}$. The best covered area is certainly the summit of the volcano, where the shallow events can be located with high accuracy (errors $<1 \mathrm{~km}$ ). Figures $8 \mathrm{~b}$ and $9 \mathrm{~b}$ show that the addition of CS allows a considerable extension, mainly to the south region. Both the latitude and longitude error would be considerably reduced (Figs. 8c and 9c) for shallow events and for those with hypocentral depth up to about $10 \mathrm{~km}$. The hypocentral depth error, which has a minimum in the central part of the edifice, at about $3 \mathrm{~km}$ of depth, would be reduced but only in a small volume in the southern sector of the Etna volcano.

\section{Conclusive remarks}

The analysis of seismic activity is considered one of the most important components of volcanic surveillance. Many of the seismic observations performed at most active volcanoes are still obtained by using only a small number of instruments and only for a number of volcanoes with dozens of instruments. However, the success of most recent seismological studies relies on the accuracy of earthquake locations. The goodness of hypocenter locations is governed by several factors, including the network geometry, available phases, arrival time reading accuracy, and knowledge of the crustal structure (see e.g. Mostaccio et al., 2013 and references therein).

The main focus of this work was to investigate the performances of the current permanent seismic network of Mt. Etna by applying the SNES method (D'Alessandro et al., 2011a). The main advantage of the SNES method is that we can evaluate the improvement of the network before the actual installation of the stations. This analysis was carried out to evaluate possible future changes in the network geometry in order to improve earthquake locations for surveillance on the Etna volcano.

Thanks to this first application of the SNES method, we have identified some critical issues of the current ESN related to the lack of seismic stations in the southern sector of the volcano, which is nevertheless affected by major seismogenic structures. Our analysis showed that the addition of stations at the CS would greatly extend the coverage of the ESN to the south and significantly reduce the errors in the hypocenter parameters estimation.

The areas that would most benefit would be surely those marked by the presence of the Pernicana Fault System and by the Trecastagni and Tremestieri Faults. This structural reinforcement will allow significant advances in the study of the dynamics of volcanoes thereby advancing research on precursory phenomena and eruptive processes.

The determination of the hypocentral parameters and source mechanisms requires an accurate and realistic velocity model, which in a volcanic area, characterized by an irregular surface topography and complex geological structures, can only be represented by fully 3-D velocity models. Furthermore, the importance of the source-receiver geometry and how the azimuthal gap and the epicentral distance to the closest station both influence the quality of the hypocenter location, is also well known and confirmed by some performed tests at Mt. Etna (Mostaccio et al., 2013). In particular, the nearest station distance is confirmed as one of the most important constraints for the accuracy of the 
focal depth, especially for the shallower earthquakes, even if a dense network is available like that of Mt. Etna.

Future efforts will be made to further enhance the operational capabilities in research and volcanic monitoring in southern Italy. A further improvement of the network could be obtained for example through its extension to the offshore area. This could be done through the deployment of an array of submarine stations in the Ionian sea (D'Alessandro et al., 2009, 2012b, 2013b).

Given the high costs and considerable efforts needed for the installation of a new seismic station, especially in a volcanic or offshore area, a preliminary evaluation of the performance improvement would be appropriate. The procedure adopted in this paper, based on the SNES method proposed by D'Alessandro et al. (2011a), allows to easily evaluate the network improvement not only after the addition of one or more stations, but and also after their shifting or removal, thus obtaining an effective network optimization and optimal management of resources.

Acknowledgements. We would like to thank all those who contribute to the maintenance and development of the seismic network managed by INGV - Osservatorio Etneo. In particular, we are grateful to the colleagues of the technical staff, Cappuccio P., Contraffatto D., La Rocca G., Sassano M., Scuderi L. and to Aiesi G., Cantarero M., Ferrari F and Messina A. for their competence and availability. We wish to thank D. Patanè for promoting technological development of the INGV seismic network. Helpful suggestions by R. Azzaro are also highly appreciated. This work has been carried out in the framework of the VULCAMED project, developed under the National Operational Programme "Research and Competitiveness" 2007-2013.

\section{References}

Alparone, S., Barberi, G., Cocina, O., Giampiccolo, E., Musumeci, C., and Patanè, D.: Intrusive mechanism of the 2008-2009 Mt. Etna eruption: Constraints by tomographic images and stress tensor analys, J. Volcanol. Geoth. Res., 229-230, 50-63, doi:10.1016/j.jvolgeores.2012.04.001, 2012.

Arevalo, C. M., Patanè, D., Rietbrock, A., and Ibánez, J. M.: The intrusive process leading to the Mt. Etna 2001 flank eruption: Constraints from 3-D attenuation tomography, Geophys. Res. Lett., 32, L21309, doi:10.1029/2005GL023736, 2005.

Azzaro, R.: Seismicity and active tectonics in the Etna region: constraints for a seismotectonic model, edited by: Bonaccorso, A., Calvari, S., Coltelli, M., Del Negro, C., and Falsaperla, S., Mt. Etna: Volcano Laboratory, AGU Monograph, 143, 205-220, 2004.

Azzaro, R., Branca, S., Gwinner, K., and Coltelli, M.: The volcanotectonic map of Etna volcano, 1:100.000 scale: an integrated approach based on a morphotectonic analysis from high-resolution DEM constrained by geologic, active faulting and seismotectonic data, Ital. J. Geosci., 131, 153-170, doi:10.3301/IJG.2011.29, 2012.
Azzaro, R., D'Amico, S., Peruzza, L., and Tuvè, T.: Probabilistic seismic hazard at Mt. Etna (Italy): the contribution of local fault activity in mid-term assessment, Journal of Volcanology and Geothermal Research, 251, 158-169, 2013.

Barberi, G., Cocina, O., Maiolino, V., Musumeci, C., and Privitera, E.: Insight into Mt. Etna (Italy) kinematics during the 2002-2003 eruption as inferred from seismic stress and strain tensors, Geophys. Res. Lett., 31, L21614, doi:10.1029/2004GL020918, 2004.

Bonforte, A., Bonaccorso, A., Guglielmino, F., Palano, M., and Puglisi, G.: Feeding system and magma storage beneath Mt. Etna as revealed by recent inflation/deflation cycles, J. Geophys. Res., 113, B05406, doi:10.1029/2007JB005334, 2008.

Bonaccorso, A., D’Amico, S., Mattia, M., and Patanè, D.: Intrusive Mechanisms at Mt. Etna Forerunning the July-August 2001 Eruption from Seismic and Ground Deformation Data, Pure Appl. Geophys., 161, 1469-1487, doi:10.1007/s00024-0042515-4, 2004.

Bottari, A. and Riuscetti, M.: La stazione sismica di Serra la Nave sull'Etna, Ann. Geofis., 20, 243-264, 1967.

Branca, S. and Del Carlo, P.: Eruptions of Mt. Etna during the past 3,200 years: A revised compilation integrating the historical and stratigraphic records, in Mt. Etna: Volcano Laboratory, Geophys. Monogr. Ser, vol. 143, edited by: Bonaccorso, A., Calvari, S., Coltelli, M., Del Negro, C., and Falsaperla, S., 1-27, AGU, Washington, D.C., 2004.

D'Alessandro, A. and D'Anna, G.: Suitability of low-cost three-axis MEMS accelerometers in strong-motion seismology: Tests on the LIS331DLH (iPhone) accelerometer, B. Seismol. Soc. Am. 103, 2906-2913, doi:10.1785/0120120287, 2013.

D'Alessandro, A. and Ruppert, N.: Evaluation of Location Performance and Magnitude of Completeness of Alaska Regional Seismic Network by SNES Method, Bull. Seismol. Soc. Am., 102, 2098-2115, doi:10.1785/0120110199, 2012.

D'Alessandro, A. and Stickney, M.: Montana Seismic Network Performance: an evaluation through the SNES method, Bull. Seismol. Soc. Am., 102, 73-87, doi:10.1785/0120100234, 2012.

D’Alessandro, A., D’Anna, G., Luzio, D., and Mangano, G.: The INGV's new OBS/H: analysis of the signals recorded at the Marsili submarine volcano, J. Volcanol. Geoth. Res., 183, 17-29, doi:10.1016/j.jvolgeores.2009.02.008, 2009.

D’Alessandro, A., Luzio, D., D’Anna, G., and Mangano, G.: Seismic Network Evaluation through Simulation: An Application to the Italian National Seismic Network, Bull. Seismol. Soc. Am., 101, 1213-1232, doi:10.1785/0120100066, 2011 a.

D'Alessandro, A., Papanastassiou, D., and Baskoutas, I.: Hellenic Unified Seismological Network: an evaluation of its performance through SNES method, Geophys. J. Int., 185, 1417-1430, doi:10.1111/j.1365-246X.2011.05018.x, 2011b.

D'Alessandro, A., Danet, A., and Grecu, B.: Location Performance and Detection Magnitude Threshold of the Romanian National Seismic Network, PAGEOPH, 169, 2149-2164, doi:10.1007/s00024-012-0475-7, 2012a.

D’Alessandro, A., Mangano, G., and D'Anna, G.: Evidence of persistent seismo-volcanic activity at Marsili seamount, Ann. Geophy., 55, 213-214, doi:10.4401/ag-5515, 2012b.

D’Alessandro, A., Badal, J., D’Anna, G., Papanastassiou, D., Baskoutas, I., and Özel, M. M.: Location performance and detection threshold of the Spanish National Seismic Network, Pure and Applied Geophysics, doi:10.1007/s00024-012-0625-y, $2013 \mathrm{a}$. 
D’Alessandro, A., Mangano, G, D’Anna, G., and Luzio, D.: Waveforms clustering and single-station location of microearthquake multiplets recorded in the northern Sicilian offshore region, Geophysical Journal International, 194, 17891809, doi:10.1093/gji/ggt192, 2013b.

D'Alessandro, A., Gervasi, A., and Guerra, I.: Evolution and strengthening of the Calabrian Regional Seismic Network, Adv. Geosci., 36, 11-16, doi:10.5194/adgeo-36-11-2013, 2013.

Di Grazia, G., Falsaperla, S., and Langer, H.: Volcanic tremor location during the 2004 Mount Etna lava effusion, Geophys. Res. Lett., 33, L04304, doi:10.1029/2005GL025177, 2006.

Gambino, S., Mostaccio, D., Patanè, D., Scarfì, L., and Ursino, A.: High-precision locations of the microseismicity preceding the 2002-2003 Mt. Etna eruption, Geophys. Res. Lett., 31, LI8604, doi:10.1029/2004GL020499, 2004.

Langer, H., Falsaperla, S., Messina, A., Spampinato, S., and Bencke, B.: Detecting imminent eruptive activity at Mt Etna, Italy, in 2007-2008 through pattern classification of volcanic tremor data, J. Volcanol. Geotherm. Res., 200, 1-17, doi:10.1016/j.jvolgeores.2010.11.019, 2011.
Mostaccio, A., Tuvè, T., Patanè, D., Barberi, G., and Zuccarello, L.: Improving Seismic Surveillance at Mt. Etna Volcano by Probabilistic Earthquake Location in a 3D Model, Bull. Seism. Soc. Am., 103, 2447-2459, doi:10.1785/0120110202, 2013.

Patanè, D., Cocina, O., Falsaperla, S., Privitera, E., and Spampinato, S.: Mt. Etna volcano: a seismological framework, edited by: Bonaccorso, A., Calvari, S., Coltelli, M., Del Negro, C., and Falsaperla, S., Mt. Etna: Volcano Laboratory, AGU Monograph, 143, 147-165, 2004.

Patanè, D., Mattia, M., and Aloisi, M.: Shallow intrusive processes during 2002-2004 and current volcanic activity on Mt. Etna, Geophys. Res. Lett., 32, L06302, doi:10.1029/2004GL021773, 2005.

Scarfî, L., Messina, A., and Cassisi, C.: Sicily and southern Calabria focal mechanism database: a valuable tool for local and regional stress-field determination, Annals of Geophysics, 56, 116, doi:10.4401/ag-6109, 2013. 